\title{
Calcification of thyroid nodules increases shear-wave speed (SWS) measurement: using multiple calcification-specific SWS cutoff values outperforms a single uniform cutoff value in diagnosing malignant thyroid nodules
}

\author{
Bao-Ding Chen ${ }^{1,2,3,4,5}$, Hui-Xiong Xu1,2,3,4, Yi-Feng Zhang ${ }^{1,2,3,4}$, Bo-Ji Liu' ${ }^{1,2,3,4}$, Le-Hang \\ Guo ${ }^{1,2,3,4}$, Dan-Dan Li ${ }^{1,2,3,4}$, Chong-Ke Zhao ${ }^{1,2,3,4}$, Xiao-Long Li ${ }^{1,2,3,4}$, Dan Wang ${ }^{1,2,3,4}$ \\ and Shuang-Shuang Zhao ${ }^{5}$ \\ ${ }^{1}$ Department of Medical Ultrasound, Shanghai Tenth People's Hospital, Ultrasound Research and Educational Institute, Tongji \\ University School of Medicine, Shanghai, China \\ 2 Department of Medical Ultrasound, Shanghai Tenth People's Hospital, Clinical College of Nanjing Medical University, \\ Shanghai, China \\ ${ }^{3}$ Thyroid Institute, Tongji University School of Medicine, Shanghai, China \\ ${ }^{4}$ Shanghai Center of Thyroid Diseases, Shanghai, China \\ ${ }^{5}$ Department of Medical Ultrasound, Affiliated Hospital of Jiangsu University, Zhenjiang, China \\ Correspondence to: Hui-Xiong Xu, email: xuhuixiong@126.com
}

Keywords: thyroid nodule, calcification, ultrasound, shear-wave elastography, point shear-wave measurement

Received: June 30, $2016 \quad$ Accepted: August 26, $2016 \quad$ Published: August 31, 2016

\section{ABSTRACT}

Conventional ultrasound cannot satisfactorily distinguish malignant and benign thyroid nodules. Shear-wave elastography (SWE) can evaluate tissue stiffness and complement conventional ultrasound in diagnosing malignant nodules. However, calcification of nodules may affect the results of SWE. The purposes of this study are to compare the differences of shear-wave speed (SWS) measurement among different calcification groups and compare the diagnostic performance between using a single uniform SWS cutoff value and multiple individual calcification-specific cutoff values using technique of point SWS measurement. We retrospectively identified 517 thyroid nodules ( 346 benign and 171 malignant nodules) examined by conventional ultrasound and point SWS measurement. There were 177 non-calcified, 159 microcalcified and 181 macro-calcified nodules. The diagnostic performance was evaluated by receiver operating characteristic (ROC) curve and area under the curve (AUC) was computed. The mean SWS in malignant nodules more than doubled that of benign nodules $(4.81 \pm 2.03 \mathrm{~m} / \mathrm{s}$ vs. $2.29 \pm 0.99 \mathrm{~m} / \mathrm{s}, \mathrm{p}<0.001)$. The mean $\mathrm{sWS}$ of nodules progressively increased from the non-calcification $(2.60 \pm 1.49 \mathrm{~m} / \mathrm{s})$, to microcalcification $(3.27 \pm 1.85 \mathrm{~m} / \mathrm{s})$ and to macro-calcification $(3.68 \pm 2.26 \mathrm{~m} / \mathrm{s})$ groups $(p<0.001)$, which was true in both the benign and malignant nodules. If we used individual SWS cutoff values for non- (SWS $>2.42 \mathrm{~m} / \mathrm{s}$ ), $\operatorname{micro-}$ (SWS $>2.88 \mathrm{~m} / \mathrm{s}$ ) and macro-calcification (SWS $>3.59 \mathrm{~m} / \mathrm{s}$ ) nodules in the whole group, the AUC was 0.859 (95\% confidence interval $[\mathrm{CI}], 0.826-0.888)$, which was significantly better than the AUC of $0.816(95 \% \mathrm{CI}, 0.780-0.848)$ if a single uniform cutoff value (SWS $>2.72 \mathrm{~m} / \mathrm{s}$ ) was applied to all the nodules regardless of calcification status $(p=0.011)$. The cutoff values of SWS for different calcified nodules warrant future prospective validation. 


\section{INTRODUCTION}

The incidences of thyroid nodules and thyroid cancer are increasing worldwide, largely due to enhanced diagnostic practices [1-4]. China has by far the largest population in the world and the burden of clinical management of thyroid nodules and thyroid cancer is enormous. A recent large community-based study revealed a thyroid nodule prevalence of $49 \%$ in Chinese adults by conventional ultrasound examination [3]. Nevertheless, only a small percentage of thyroid nodules are malignant [5]. It is critical to differentiate malignant from benign thyroid nodules and avoid unnecessary fine needle aspiration (FNA) biopsy and surgery. Conventional B-mode (brightness mode, or 2D mode) ultrasound is the most commonly used method to detect and evaluate thyroid nodules. Conventional ultrasound imaging characteristics associated with malignant nodules include the presence of micro-calcifications, hypoechogenicity, size greater than $2 \mathrm{~cm}$, taller-than wide shape, and an entirely solid composition [6], but these features have varing sensitivity and specificity for diagnosing malignant thyroid nodules [7].

In recent decade, there have been many studies evaluating whether elastography, a non-invasive ultrasound method to measure tissue stiffness, can complement conventional ultrasound in differentiating malignant from benign nodules [8]. Conventional ultrasound images reveal differences in the acoustic properties of soft tissues, whereas elastography is able to reveal the differences in the elastic properties of soft tissues [9]. It is known that cancer tissues are stiffer than normal tissues [8]. There are two types of elastography, strain elastography (SE) and shear-wave elastography (SWE). Conventional SE requires manual compression by the operator, which can only produce semi-quantitative images and cannot precisely measure tissue stiffness. In contrast, SWE includes shear-wave speed (SWS) imaging and point shear-wave speed (pSWS) measurement, which can evaluate the tissue stiffness qualitatively and quantitatively by monitoring the SWS propagation in tissues $[9,10]$. A number of studies [11-14] have shown that SWE is a promising complementary ultrasound technique for differentiating malignant and benign thyroid nodules.

Several factors can affect the results of elastography, particularly calcification in nodules [15-17]. Veyrieres et al. [17] reported that calcification in thyroid nodules increased SWS values on pSWS measurement, thus resulting in higher number of false positive nodules when a uniform cutoff value of SWS was applied for noncalcified and calcified nodules. Some prior studies simply excluded calcified nodules from their analysis to avoid this problem [18]. However, excluding calcified nodules in SWS analysis may miss a significant number of true malignant nodules, because calcified nodules account for $19.8-38.6 \%$ of all thyroid nodules $[19,20]$ and carry a doubled risk of being malignant nodules compared to non-calcified nodules [21-24].

The purposes of this study were to compare the differences of SWS on pSWS measurement among nodules with different calcifications (non-, micro-, and macrocalcification) and to compare the diagnostic performance between a single cutoff value and individually defined cutoff values of SWS in diagnosing malignant thyroid nodules.

\section{RESULTS}

\section{Basic characteristics of patients and nodules}

There were 517 thyroid nodules in 498 patients, including $346(66.3 \%)$ benign and 171 (33.7\%) malignant nodules. Among 498 patients, 107 were men and 391 were women, and the mean age $( \pm \mathrm{SD})$ of patients was $51.5 \pm 12.9$ years (range, 18-82 years). Based on the pattern of calcification in nodule, these thyroid nodules were classfied into non-calcification $(\mathrm{n}=177)$, microcalcification $(\mathrm{n}=159)$ and macro-calcification groups $(\mathrm{n}=181)$. There were 140 benign and 37 malignant noncalcified nodules, 94 benign and 65 malignant microcalcified nodules, and 112 benign and 69 malignant macro-calcified nodules. The mean size $( \pm \mathrm{SD})$ of nodules was $20.1 \pm 9.2 \mathrm{~mm}$, ranging from 10.0 to $62.6 \mathrm{~mm}$. There were statistically significant differences in terms of patient age, calcified pattern of nodule, size of nodule, maximum SWS of nodule, and mean SWS of nodule between the benign and malignant groups (Table 1).

\section{Features of nodules among different calcification groups}

The distribution of benign vs. malignant nodule, conventional SE score, ARFI SE grade, maximum SWS of nodule, and mean SWS of nodule were significantly different among non-calcification, micro-calcification and macro-calcification groups, whereas patient age, sex, size of nodule, maximum SWS and mean SWS of surrounding tissue were not significantly different. The percentages of malignant nodules in the macro- and micro-calcification groups were $38.1 \%$ and $40.9 \%$ respectively, compared to $20.9 \%$ in the non-calcification group $(p<0.001)$. Both the mean and the maximum SWSs of nodule progressively increased from the non-calcification, to micro-calcification and to macro-calcification groups: the mean SWS values of non-, micro-, and macro-calcified nodules were $2.60 \pm 1.49 \mathrm{~m} / \mathrm{s}, 3.27 \pm 1.85 \mathrm{~m} / \mathrm{s}$, and $3.68 \pm 2.26 \mathrm{~m} / \mathrm{s}$, respectively ( $p=0.001$ ), and the maximum SWS in these three groups were $3.31 \pm 2.01 \mathrm{~m} / \mathrm{s}, 4.64 \pm 2.64 \mathrm{~m} / \mathrm{s}$, and $4.79 \pm 2.67 \mathrm{~m} / \mathrm{s}$, respectively $(p=0.001)$ (Table 2$)$. This 
Table 1: Basic characteristics of patients and nodules

\begin{tabular}{|l|l|l|l|l|}
\hline Characteristics & $\begin{array}{l}\text { Whole group * } \\
(\mathbf{n}=\mathbf{5 1 7})\end{array}$ & $\begin{array}{l}\text { Benign group * } \\
(\mathbf{n = 3 4 6 )}\end{array}$ & $\begin{array}{l}\text { Malignant group * } \\
(\mathbf{n}=\mathbf{1 7 1})\end{array}$ & $\boldsymbol{P}$ value @ \\
\hline No. of patients & 498 & 330 & 168 & \\
\hline Age (yr) \# & $51.5 \pm 12.9[18-82]$ & $52.6 \pm 13.2[18-82]$ & $49.3 \pm 12.3[23-78]$ & 0.006 \\
\hline Males/females & $107 / 391$ & $78 / 253$ & $29 / 138$ & 0.127 \\
\hline Pattern of nodule & & & & $<0.001$ \\
\hline Non-calcification & $177(34.2)$ & $140(40.5)$ & $37(21.7)$ & \\
\hline Micro-calcification & $159(30.8)$ & $94(27.2)$ & $65(38.0)$ & \\
\hline Macro-calcification & $181(35.0)$ & $112(32.3)$ & $69(40.3)$ & \\
\hline Size $(\mathrm{mm}) \#$ & $20.1 \pm 9.2[10.0-62.6]$ & $21.3 \pm 10.1[10.0-62.6]$ & $17.6 \pm 6.5[10.0-39.2]$ & $<0.001$ \\
\hline No. of 10-20 mm & $363(70.2)$ & $220(63.6)$ & $143(83.6)$ & \\
\hline No. of $>20$ mm & $154(29.8)$ & $126(36.4)$ & $28(16.4)$ & \\
\hline Maximum SWS of nodule \# (m/s) & $4.24 \pm 2.55[0.54-8.40]$ & $3.47 \pm 2.16[0.54-8.40]$ & $5.81 \pm 2.56[1.17-8.40]$ & $<0.001$ \\
\hline Mean SWS of nodule \# (m/s) & $3.12 \pm 1.84[0.35-8.40]$ & $2.29 \pm 0.99[0.35-6.12]$ & $4.81 \pm 2.03[1.42-8.40]$ & $<0.001$ \\
\hline $\begin{array}{l}\text { Maximum SWS of surrounding } \\
\text { tissue \# (m/s) }\end{array}$ & $2.60 \pm 0.80[0.82-7.64]$ & $2.56 \pm 0.92[0.82-7.64]$ & $2.56 \pm 0.73[0.90-5.88]$ & 0.095 \\
\hline $\begin{array}{l}\text { Mean SWS of surrounding tissue \# } \\
\text { (m/s) }\end{array}$ & $2.28 \pm 0.74[0.42-6.24]$ & $2.25 \pm 0.76[0.66-6.24]$ & $2.31 \pm 0.69[0.42-5.34]$ & 0.420 \\
\hline
\end{tabular}

* Numbers in parentheses are percentages.

\# Data are means \pm standard deviations. Ranges are in brackets.

(a) $P$ values of nonparametric variables were determined by Chi-square test, and $P$ values of continuous variables by independent $t$ test.

Abbreviation: SWS, shear-wave speed.

progressive increase of SWS values with the increasing level of calcification was observed in both benign and malignant nodules (Table 3). In contrast to SWS values, the conventional SE scores and ARFI SE grades were not significantly different among the three different calcification nodule groups in either benign or malignant nodules (Table 3). Figures 1 and 2 showed representative images and histology of non-, micro- and macro-calcified benign and malignant nodules, respectively.

\section{Cutoff values of elastography for diagnosing malignant nodules in different groups}

We then compared the optimal cutoff values of different elastography measurements among the different calcification groups at which the maximal YI, 90\% sensitivity or $90 \%$ specificity were achieved (Table 4). The cutoff values of SWS of nodule were significantly different among different calcification groups ( $p$ $=0.03$ ), and increased from non-calcification, to microcalcification, and to macro-calcification groups. Based on the maximum YI, the optimal cutoff values of SWS for diagnosing malignancy in non-, micro-, and macrocalcification nodules were $2.42 \mathrm{~m} / \mathrm{s}, 2.88 \mathrm{~m} / \mathrm{s}$, and 3.59 $\mathrm{m} / \mathrm{s}$, respectively. At $90 \%$ sensitivity, the cutoff values of SWS in the non-, micro-, and macro-calcification groups were $2.38 \mathrm{~m} / \mathrm{s}, 2.71 \mathrm{~m} / \mathrm{s}$, and $2.76 \mathrm{~m} / \mathrm{s}$ respectively, and the corresponding cutoff values to give $90 \%$ specificity were $2.67 \mathrm{~m} / \mathrm{s}, 3.24 \mathrm{~m} / \mathrm{s}$, and $3.99 \mathrm{~m} / \mathrm{s}$, respectively. In contrast, the diagnostic cutoff values of conventional SE score and
ARFI SE grade in different calcification groups were not significantly different ( $p=0.916$ and 0.848 , respectively).

\section{The diagnostic performances of applying a single uniform or multiple individual SWS cutoff values}

If we used individual SWS cutoff points for non( $\mathrm{SWS}>2.42 \mathrm{~m} / \mathrm{s}$ ), micro- (SWS $>2.88 \mathrm{~m} / \mathrm{s}$ ) and macrocalcification (SWS $>3.59 \mathrm{~m} / \mathrm{s}$ ) nodules in the whole group, the AUC was 0.859 (95\% CI, 0.826-0.888), significantly better than the AUC of $0.816(95 \% \mathrm{CI}, 0.780-0.848)$ if a single uniform cutoff value ( $\mathrm{SWS}>2.72 \mathrm{~m} / \mathrm{s}$ ) was applied to all the nodules regardless of calcification status $(p=0.011)$ (Table 5). Applying these distinct SWS cutoff values for different calcification groups, the AUCs in the non-, micro- and macro-calcification groups were 0.906 (95\% CI, 0.853-0.945), 0.871 (95\% CI, 0.809-0.919) and 0.805 ( $95 \% \mathrm{CI}, 0.740-0.860$ ) respectively, all higher than corresponding AUCs of 0.799 (95\% CI, 0.732-0.855), 0.859 (95\% CI, 0.795-0.909) and 0.698 (95\% CI, $0.625-$ $0.764)$ when a single uniform SWS cutoff value $(>2.72$ $\mathrm{m} / \mathrm{s}$ ) was used. The main effect of applying calcificationspecific individual SWS cutoff values in the whole group was specificity, positive predictive value (PPV), and YI, whereas sensitivity and negative predictive value (NPV) was comparable. The specificities in the whole group using multiple individual and single uniform cutoff values were $87.0 \%$ and $76.0 \%$ respectively; the PPV was $76.3 \%$ and $64.2 \%$, and the YI was 0.718 and 0.631 , respectively (Table 5). 

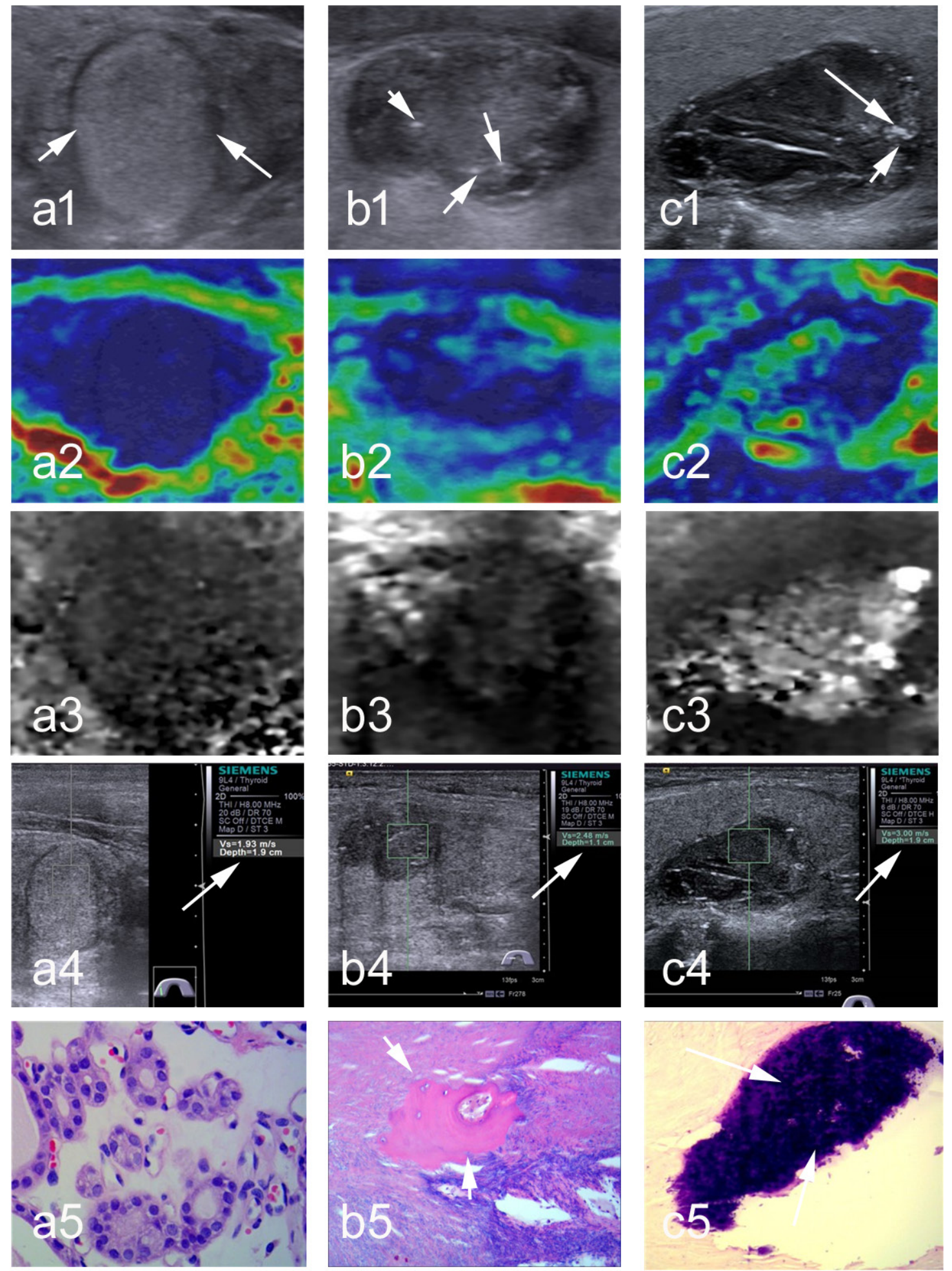

Figure 1: Representative images and histology of non-calcified, micro-calcified and macro-calcified benign thyroid nodules. (a1) At conventional ultrasound, a non-calcified nodule is $16 \mathrm{~mm}$ in dimension, solid, isoechogenic, well defined, taller than wide; (a2-a3) at SE, conventional SE score is 4, and ARFI SE grade is 3; (a4) at SWE, the SWS of $1.96 \mathrm{~m} / \mathrm{s}$ in nodule is assigned (arrow); (a5) Surgery histology confirms a follicular thyroid adenoma $(\times 400)$. (b1) At conventional ultrasound, a micro-calcified (arrows) nodule is $14 \mathrm{~mm}$ in dimension, solid, hypoechogenic, poorly defined, wider than tall; (b2-b3) at SE, conventional SE score is 3, and ARFI SE grade is 3; (b4) at SWE, SWS of $2.48 \mathrm{~m} / \mathrm{s}$ in nodule is assigned (arrow); (b5) Surgery histology confirms the Hashimoto's nodule with micro-calcified foci (arrow, $\times 400$ ). (c1) At conventional ultrasound, a macro-calcified (arrows) nodule is 21-mm in dimension, solid, hypoechogenic, well defined, taller than wide; (c2-c3)at SE, conventional SE score is 2, ARFI SE grade is 2; (c4) at SWE, SWS of $3.00 \mathrm{~m} / \mathrm{s}$ in nodule is assigned; (c5) Surgery histology confirms a nodular goiter with macro-calcified foci (arrow, $\times 100$ ). 

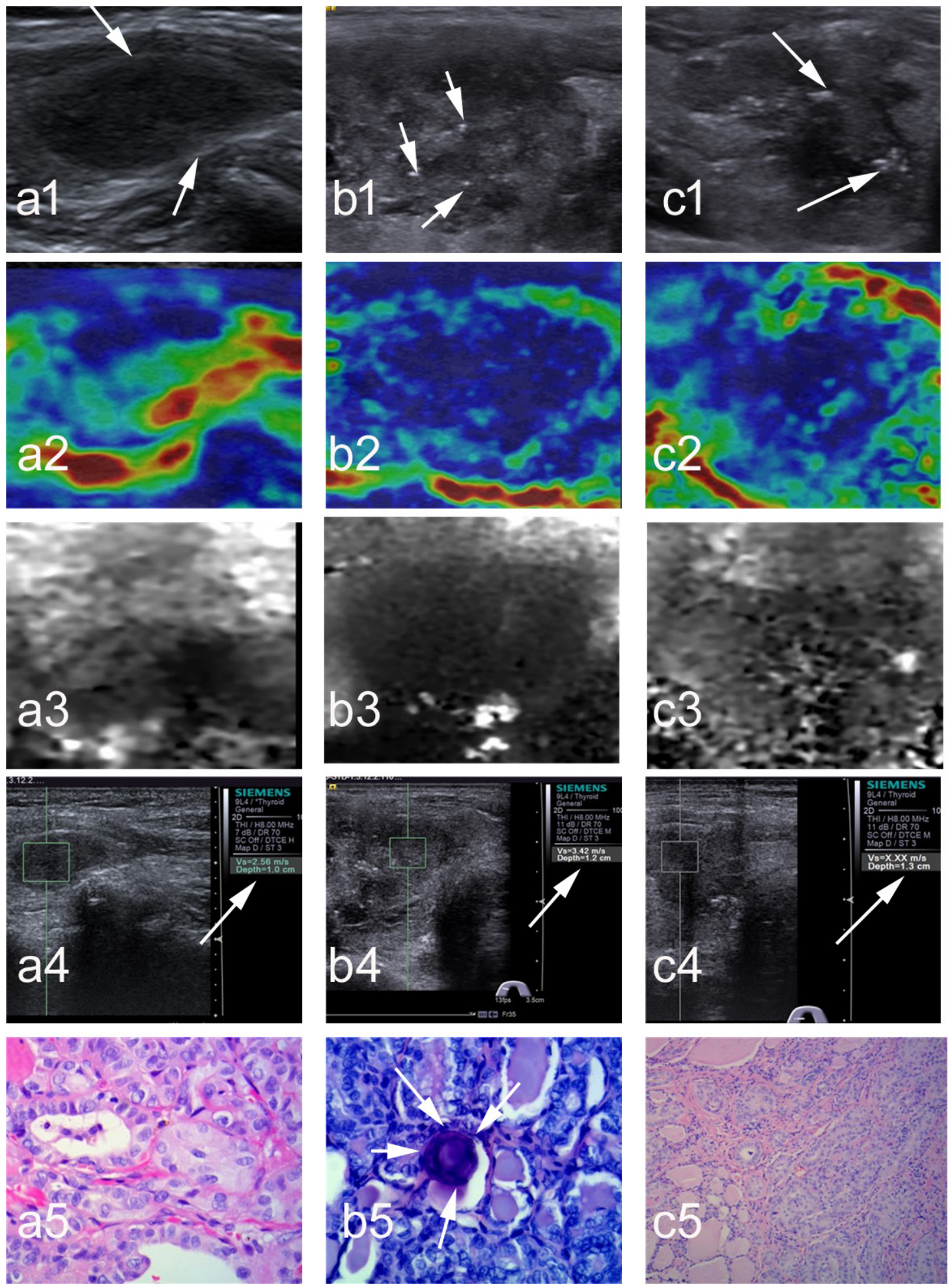

Figure 2: Representative images and histology of non-calcified, micro-calcified and macro-calcified malignant thyroid nodules. (a1) At conventional ultrasound, a non-calcified nodule is $13 \mathrm{~mm}$ in dimension, solid, hypoechogenic, well defined, wider than tall; (a2-a3)at SE, conventional SE score is 2, and ARFI SE grade is 2; (a4) at SWE, SWS of $2.56 \mathrm{~m} / \mathrm{s}$ in nodule is assigned (arrows); (a5) Surgery histology confirms a papillary thyroid carcinoma $(\times 400)$. (b1) At conventional ultrasound, a micro-calcified (arrows) nodule is 22 $\mathrm{mm}$ in dimension, solid, hypoechogenic, irregular, wider than tall; (b2-b3) at SE, conventional SE score is 4, and ARFI SE grade is 4; (b4) at SWE, SWS of $3.42 \mathrm{~m} / \mathrm{s}$ in nodule is assigned (arrow); (b5) Surgery histology confirms a papillary thyroid carcinoma with micro-calcified foci (arrows, $\times 400$ ). (c1) At conventional ultrasound, a macro-calcified (arrows) nodule is $25 \mathrm{~mm}$ in dimension, solid, hypoechogenic, well defined, wider than tall; (c2-c3) at SE, conventional SE score is 3, and ARFI SE grade is 3; (c4) at SWE, SWS of "X.XX m/sec" (i.e., 8.4 $\mathrm{m} / \mathrm{s})$ is assigned (arrow); (c5) Surgery histology confirms a papillary thyroid carcinoma $(\times 400)$. 
Table 2: Features of nodules in different calcification groups

\begin{tabular}{|c|c|c|c|c|}
\hline Features & \begin{tabular}{|l|}
$\begin{array}{l}\text { Non-calcification } \\
\text { group* }(\mathrm{n}=177)\end{array}$ \\
\end{tabular} & \begin{tabular}{|l|}
$\begin{array}{l}\text { Micro-calcification } \\
\text { group* }(\mathrm{n}=159)\end{array}$ \\
\end{tabular} & \begin{tabular}{|l|}
$\begin{array}{l}\text { Macro-calcification } \\
\text { group * }(\mathrm{n}=181)\end{array}$ \\
\end{tabular} & $P$ value \\
\hline No. of males/females & $34 / 143$ & $39 / 120$ & $38 / 143$ & 0.488 \\
\hline Age \# & $49.8 \pm 13.6[18-80]$ & $52.5 \pm 13.3[23-82]$ & $52.4 \pm 12.0[23-78]$ & 0.134 \\
\hline No. of nodules & 177 & 159 & 181 & $<0.001$ \\
\hline No. of benign nodules & $140(79.1)$ & $94(59.1)$ & $112(61.9)$ & \\
\hline No. of malignant nodules & $37(20.9)$ & $65(40.9)$ & $69(38.1)$ & \\
\hline Size $(\mathrm{mm}) \#$ & $20.3 \pm 10.9[10.0-62.6]$ & $19.6 \pm 8.7[10.0-59.7]$ & $20.3 \pm 8.0[12.3-53.3]$ & 0.748 \\
\hline Conventional SE score & & & & 0.041 \\
\hline \begin{tabular}{|l|} 
No. of score 1 \\
\end{tabular} & $1(0.6)$ & $0(0)$ & $0(0)$ & \\
\hline No. of score 2 & $41(23.2)$ & $31(19.4)$ & $40(22.1)$ & \\
\hline No. of score 3 & $93(52.5)$ & $64(40.3)$ & $73(40.3)$ & \\
\hline No. of score 4 & $35(19.7)$ & $48(30.2)$ & $54(29.8)$ & \\
\hline No. of score 5 & $7(4.0)$ & $16(10.1)$ & $14(7.7)$ & \\
\hline ARFI SE grade & & & & 0.012 \\
\hline No. of grade 1 & $1(0.6)$ & $1(0.6)$ & 0() & \\
\hline No. of grade 2 & $41(23.2)$ & $21(13.2)$ & $34(18.0)$ & \\
\hline No. of grade 3 & $89(50.3)$ & $63(39.6)$ & $83(45.9)$ & \\
\hline \begin{tabular}{|l|} 
No. of grade 4 \\
\end{tabular} & $34(19.2)$ & $41(25.8)$ & $41(22.7)$ & \\
\hline No. of grade 5 & $10(5.6)$ & $30(18.9)$ & $22(12.2)$ & \\
\hline No. of grade 6 & $2(1.1)$ & $3(1.9)$ & $1(0.6)$ & \\
\hline Maximum SWS of nodule \# $(\mathrm{m} / \mathrm{s})$ & $3.31 \pm 2.01[0.56-8.40]$ & $4.64 \pm 2.64[0.70-8.40]$ & $\begin{array}{l}4.79 \pm 2.67 \quad[0.54- \\
8.40]\end{array}$ & $<0.001$ \\
\hline Mean SWS of nodule \# $(\mathrm{m} / \mathrm{s})$ & $2.60 \pm 1.49[0.43-8.21]$ & $3.27 \pm 1.85[0.85-8.01]$ & $\begin{array}{l}3.68 \pm 2.26 \quad[0.41- \\
8.32]\end{array}$ & $<0.001$ \\
\hline $\begin{array}{l}\text { Maximum SWS of surrounding } \\
\text { tissue } \#(\mathrm{~m} / \mathrm{s})\end{array}$ & $2.55 \pm 0.78[0.91-5.88]$ & $2.60 \pm 0.69[1.26-7.88]$ & $\begin{array}{llll}2.65 & \pm 0.91 \quad[0.82- \\
7.64] & & \end{array}$ & 0.466 \\
\hline $\begin{array}{l}\text { Mean SWS of surrounding tissue \# } \\
(\mathrm{m} / \mathrm{s})\end{array}$ & $2.21 \pm 0.72[0.80-5.88]$ & $2.37 \pm 0.78[1.10-6.24]$ & $\begin{array}{l}2.27 \pm 0.80 \quad[0.42- \\
6.35]\end{array}$ & 0.142 \\
\hline
\end{tabular}

* Numbers in parentheses are percentages.

\# Data are means \pm standard deviations. Ranges are in brackets.

(a) $P$ values of nonparametric variables were determined by Chi-square test, and $P$ values of continuous variables by one way analysis of variation.

Abbreviation: SE, strain elastography; ARFI, acoustic radiation force impulse; SWS, shear-wave speed.

\section{DISCUSSIONS}

The main conclusion of our study is that applying multiple individual cutoff values of SWS based on the calcification status of thyroid nodules exhibits better diagnostic performance than using a single cutoff value regardless of calcification status. In our study, the mean SWS increased progressively from non-calcification ( 2.60 $\pm 1.49 \mathrm{~m} / \mathrm{s})$, to micro-calcification $(3.27 \pm 1.85 \mathrm{~m} / \mathrm{s})$, and to macro-calcification $(3.68 \pm 2.26 \mathrm{~m} / \mathrm{s})$ groups $(p<0.001)$. Given that malignant nodules are stiffer than benign nodules [8], we further stratified nodules into malignant and benign groups and observed similar trend of increasing SWS values with higher level of calcification. Consistent with our observation, a previous report on breast lesions showed that highly dense clusters of micro-calcifications and single macro-calcification created the appearance of high SWS, and regional scattered micro-calcifications increased mean SWS by $50 \%$ and max SWS by $250 \%$ [16]. The strong effect of calcification on SWS values calls for individual cutoff points when diagnosing malignant thyroid nodules using SWE. In contrast, the cutoff values of strain elastography (conventional SE and ARFI SE) in different calcification groups were not significantly different, suggesting that the effect of calcifications on SE was weak. We also observed that the mean SWS of malignant nodules more than doubled that of benign nodules (4.81 vs. $2.29, p<0.001$, Table 1 ), confirming the ability of SWE in distinguishing malignant from benign nodules and in diagnosing malignant thyroid nodules. The SWS of surrounding tissues was similar between benign and malignant nodules, indicating the disease specificity of SWS.

YI is a summary measure of sensitivity and specificity and is widely utilized in studies evaluating accuracy of diagnostic tests [25-27]. To achieve maximum YI, the cutoff values of SWS for thyroid nodules were 2.72 
Table 3:The elastography features of differently calcified nodules in benign and malignant groups

\begin{tabular}{|c|c|c|c|c|c|c|c|c|}
\hline \multirow[b]{2}{*}{ Features } & \multicolumn{3}{|l|}{ Benign group } & \multirow[b]{2}{*}{$P$ value@ } & \multicolumn{3}{|l|}{ Malignant group } & \multirow[b]{2}{*}{$\begin{array}{l}P \text { value } \\
\text { @ }\end{array}$} \\
\hline & \begin{tabular}{|l|} 
Non- \\
calcification \\
$*$ \\
$(n=140)$
\end{tabular} & $\begin{array}{l}\text { Micro- } \\
\text { calcification * } \\
(\mathrm{n}=94)\end{array}$ & $\begin{array}{l}\begin{array}{l}\text { Macro- } \\
\text { calcification * } \\
(\mathbf{n}=112)\end{array}\end{array}$ & & $\begin{array}{l}\begin{array}{l}\text { Non- } \\
\text { calcification * } \\
(\mathrm{n}=37)\end{array}\end{array}$ & $\begin{array}{l}\text { Micro- } \\
\text { calcification } \\
(\mathrm{n}=65)\end{array}$ & $\begin{array}{l}\text { Macro- } \\
\text { calcification * } \\
(\mathrm{n}=69)\end{array}$ & \\
\hline $\begin{array}{l}\text { Conventional SE } \\
\text { score }\end{array}$ & & & & 0.110 & & & & 0.242 \\
\hline Score 1 & $1(0.7)$ & $0(0)$ & $0(0)$ & & $0(0)$ & $0(0)$ & $0(0)$ & \\
\hline Score 2 & $40(28.6)$ & $26(27.7)$ & $37(33.0)$ & & $1(2.7)$ & $5(7.7)$ & $3(4.3)$ & \\
\hline Score 3 & $88(62.9)$ & $49(52.1)$ & $64(57.1)$ & & $5(13.5)$ & $15(23.1)$ & $9(13.0)$ & \\
\hline Score 4 & $9(6.4)$ & $18(19.1)$ & $9(8.0)$ & & $26(70.3)$ & $30(46.2)$ & $45(65.2)$ & \\
\hline Score 5 & $2(1.4)$ & $1(1.1)$ & $2(1.8)$ & & $5(13.5)$ & $15(23.1)$ & $12(17.4)$ & \\
\hline ARFI SE grade & & & & 0.036 & & & & 0.613 \\
\hline Grade 1 & $1(0.7)$ & $0(0)$ & $0(0)$ & & $0(0)$ & $1(1.5)$ & $0(0)$ & \\
\hline Grade 2 & $39(27.9)$ & $19(20.2)$ & $31(27.7)$ & & $2(5.4)$ & $2(3.1)$ & $3(4.3)$ & \\
\hline Grade 3 & $86(61.4)$ & $53(56.4)$ & $74(66.1)$ & & $3(8.1)$ & $10(15.4)$ & $9(13.0)$ & \\
\hline Grade 4 & $12(8.6)$ & $15(16.0)$ & $5(4.5)$ & & $22(59.5)$ & $26(40.0)$ & $36(52.2)$ & \\
\hline Grade 5 & $2(1.4)$ & $6(6.4)$ & $2(1.8)$ & & $8(21.6)$ & $24(36.9)$ & $20(29.0)$ & \\
\hline Grade 6 & $0(0)$ & $1(1.1)$ & $0(0)$ & & $2(5.4)$ & $2(3.1)$ & $1(1.4)$ & \\
\hline $\begin{array}{l}\text { Maximum SWS } \\
\text { of nodule \# }(\mathrm{m} / \mathrm{s})\end{array}$ & \begin{tabular}{|l|}
$2.91 \pm 1.74$ \\
{$[0.56-8.40]$} \\
\end{tabular} & \begin{tabular}{|lll}
3.80 & \pm & 2.39 \\
{$[1.03-8.21]$} & \\
\end{tabular} & $\begin{array}{l}3.89 \pm 2.31[0.54- \\
8.40]\end{array}$ & $<0.001$ & $\begin{array}{|ll|}4.81 & \pm \\
{[1.50-8.00]} & 2.32 \\
\end{array}$ & $\begin{array}{l}5.86 \pm 2.53[1.17- \\
8.40]\end{array}$ & $\begin{array}{l}6.27 \pm 2.56[1.40- \\
8.40] \\
\end{array}$ & 0.018 \\
\hline $\begin{array}{l}\text { Mean SWS of } \\
\text { nodule \# }(\mathrm{m} / \mathrm{s})\end{array}$ & \begin{tabular}{|l|}
$2.35 \pm 1.31$ \\
{$[0.35-8.21]$} \\
\end{tabular} & \begin{tabular}{|lll}
2.73 & \pm & 1.47 \\
{$[0.85-8.04]$} & \\
\end{tabular} & $\begin{array}{l}2.80 \pm 1.57[0.41- \\
8.11]\end{array}$ & 0.029 & $\begin{array}{|lc|}3.56 & \pm \\
{[1.40-8.12]} & 1.75 \\
\end{array}$ & $\begin{array}{l}4.05 \pm 2.07[1.05- \\
8.12]\end{array}$ & $\begin{array}{l}5.11 \pm 2.49[1.12- \\
8.32]\end{array}$ & 0.001 \\
\hline
\end{tabular}

* Numbers in parentheses are percentages.

\# Data are means \pm standard deviations. Ranges are in brackets.

(a) $P$ values of nonparametric variables were determined by Chi-square test, and $P$ values of continuous variables by one way analysis of variation.

Abbreviations: SE, strain elastography; ARFI, acoustic radiation force impulse; SWS, shear-wave speed.

Table 4: Diagnostic cutoff values of conventional SE score, ARFI SE grade, and mean SWS of nodule in the whole and different calcification groups

\begin{tabular}{|c|c|c|c|c|c|}
\hline \multirow[b]{2}{*}{ Methods } & \multirow[b]{2}{*}{ The whole group } & \multicolumn{3}{|c|}{ Calcification groups } & \multirow[b]{2}{*}{$P^{*}$ value } \\
\hline & & Non-calcification & $\begin{array}{l}\text { Micro- } \\
\text { calcification }\end{array}$ & $\begin{array}{l}\text { Macro- } \\
\text { calcification }\end{array}$ & \\
\hline Conventional SE score & & & & & 0.916 \\
\hline At the point of maximum YI & $>3$ & $>3$ & $>3$ & $>3$ & \\
\hline At the point of $90 \%$ sensitivity & $>2$ & $>2$ & $>2$ & $>2$ & \\
\hline At the point of $90 \%$ specificity & $>3$ & $>3$ & $>4$ & $>3$ & \\
\hline ARFI SE grade & & & & & 0.848 \\
\hline At the point of maximum YI & $>3$ & $>3$ & $>3$ & $>3$ & \\
\hline At the point of $90 \%$ sensitivity & $>2$ & $>3$ & $>2$ & $>2$ & \\
\hline At the point of $90 \%$ specificity & $>3$ & $>3$ & $>4$ & $>3$ & \\
\hline Mean SWS of nodules $(\mathrm{m} / \mathrm{s})$ & & & & & 0.030 \\
\hline At the point of maximum YI & $>2.72$ & $>2.42$ & $>2.88$ & $>3.59$ & \\
\hline At the point of $90 \%$ sensitivity & $>2.61$ & $>2.38$ & $>2.71$ & $>2.76$ & \\
\hline At the point of $90 \%$ specificity & $>3.47$ & $>2.67$ & $>3.24$ & $>3.99$ & \\
\hline
\end{tabular}

* Determined using one way analysis of variation in the whole and different calcification groups.

Abbreviations: SE, strain elastography; ARFI, acoustic radiation force impulse; SWS, shear-wave speed; YI, Youden index.

$\mathrm{m} / \mathrm{s}, 2.42 \mathrm{~m} / \mathrm{s}, 2.88 \mathrm{~m} / \mathrm{s}$, and $3.59 \mathrm{~m} / \mathrm{s}$, respectively in the whole, non-calcification, micro-calcification and macrocalcification groups. These values were in line with those reported in previous literatures (range, $2.42-3.39 \mathrm{~m} / \mathrm{s}$ ) [11, $13,28-31]$. In those previous reports, generally a single SWS value was applied for discriminating malignancy in the whole nodules. Our study suggests individual cutoff values of SWS according to varied calcifications in nodules.

This study had a couple of limitations. Firstly, this was a single center, retrospective study. The cutoff values of SWS in different calcification groups warrant future multi-center, prospective validation. Secondly, we did not quantify the level of calcifications in nodules but broadly 
Table 5: Comparing the diagnostic performances of pSWS for thyroid nodules between a single uniform cutoff value and individual cutoff values

\begin{tabular}{|l|l|l|l|l|l|l|l|}
\hline \multirow{2}{*}{ Group } & Sensitivity & Specificity & PPV & NPV & YI & \multicolumn{2}{l|}{ ROC } \\
\cline { 5 - 8 } & & & & & & AUC* & \multicolumn{2}{l|}{$\boldsymbol{P}$ value\# } \\
\hline Non-calcification group & & & & & & & 0.004 \\
\hline Single cutoff value $(>2.72 \mathrm{~m} / \mathrm{s})$ & $67.6 \%$ & $92.1 \%$ & $69.4 \%$ & $90.5 \%$ & 0.597 & $0.799(0.732-0.855)$ & \\
\hline Individual cutoff value $(>2.42 \mathrm{~m} / \mathrm{s})$ & $91.9 \%$ & $88.6 \%$ & $68.0 \%$ & $97.6 \%$ & 0.805 & $0.906(0.853-0.945)$ & \\
\hline Micro-calcification group & & & & & & & 0.559 \\
\hline Single cutoff value $(>2.72 \mathrm{~m} / \mathrm{s})$ & $84.6 \%$ & $87.2 \%$ & $82.1 \%$ & $89.1 \%$ & 0.718 & $0.859(0.795-0.909)$ & \\
\hline Individual cutoff value $(>2.88 \mathrm{~m} / \mathrm{s})$ & $92.3 \%$ & $81.9 \%$ & $77.9 \%$ & $93.9 \%$ & 0.742 & $0.871(0.809-0.919)$ & \\
\hline Macro-calcification group & & & & & & & $<0.001$ \\
\hline Single cutoff value $(>2.72 \mathrm{~m} / \mathrm{s})$ & $91.3 \%$ & $48.2 \%$ & $52.1 \%$ & $90.0 \%$ & 0.395 & $0.698(0.625-0.764)$ & \\
\hline Individual cutoff value $(>3.59 \mathrm{~m} / \mathrm{s})$ & $72.5 \%$ & $86.6 \%$ & $76.9 \%$ & $83.6 \%$ & 0.591 & $0.805(0.740-0.860)$ & \\
\hline Whole group & & & & & & & 0.011 \\
\hline Single cutoff value $(>2.72 \mathrm{~m} / \mathrm{s})$ & $87.1 \%$ & $76.0 \%$ & $64.2 \%$ & $92.3 \%$ & 0.631 & $0.816(0.780-0.848)$ & \\
\hline Individual cutoff values@ 0 & $84.8 \%$ & $87.0 \%$ & $76.3 \%$ & $92.0 \%$ & 0.718 & $0.859(0.826-0.888)$ & \\
\hline
\end{tabular}

* Numbers in parentheses are $95 \%$ confidence intervals.

\# Determined using Z test.

(a) SWS of nodule $>2.42 \mathrm{~m} / \mathrm{s},>2.88 \mathrm{~m} / \mathrm{s}$ and $>3.59 \mathrm{~m} / \mathrm{s}$ were for non-calcified, micro-calcified and macro-calcified nodules in the whole group.

Abbreviations: pSWS, point shear-wave speed; PPV, positive predictive value; NPV, negative predictive value; YI, Youden Index; ROC, receiver operating characteristic; AUROC, area under receiver operating characteristic curve.

categorized nodules into three groups.

In conclusion, the mean and maximum SWS of thyroid nodules increases progressively from noncalcification, to micro-calcification and to macrocalcification groups. The diagnostic performance of applying multiple individual cutoff values of pSWS for discriminating malignancy in thyroid nodules is significantly better than that applying a single uniform cutoff value. We recommend individual cutoff values of SWS for diagnosing malignant thyroid nodules with different calcifications.

\section{MATERIALS AND METHODS}

\section{Patients}

All patients were retrospectively identified from patients who came to Shanghai Tenth People's Hospital of Tongji University School of Medicine for thyroid examination. From January 2014 to November 2015. A total of 1,145 consecutive patients with 1,522 thyroid nodules received the examinations of conventional ultrasound, SE and point SWS measurement. Among these patients, 671 patients with 690 nodules met the following enrollment criteria: (1) had fine needle aspiration (FNA) cytology and/or surgery histology within a month after examinations; (2) the size of nodule was $\geq 10 \mathrm{~mm}$ in the greatest dimension; (3) solid nodules at B-mode ultrasound images; and (4) with complete medical information and no surgery treatment performed on the nodules before. Then, 172 nodules were excluded for the following reasons: (1) inadequate cytologic results and without surgery histology $(\mathrm{n}=42)$; (2) indeterminable cytologic results and without surgery histology $(\mathrm{n}=55)$; (3) being diagnosed as "suspicious for papillary thyroid carcinoma" only at cytologic examination but did not undergo surgery histology ( $\mathrm{n}=23)$; (4) nodules with annular-like peripheral macro-calcification and/or crescent-like peripheral macrocalcification ( $\mathrm{n}=21)$; and (5) clustered micro-calcification or macro-calcification foci cannot be completely avoided when measuring the SWS ( $n=31)$. Finally, 517 thyroid nodules in 498 patients were included in the analyses, including 346 benign nodules in 330 patients and 171 malignant nodules in 168 patients. Of the 346 benign nodules, 301 nodules were diagnosed by cytology and 45 nodules by surgery histology. Of the 171 malignant nodules, 26 nodules by cytology and 145 nodules by surgery histology (including 135 papillary thyroid carcinomas, 4 follicular thyroid carcinomas, 3 medullary carcinomas and 2 anaplastic carcinomas). This study was approved by the Ethical Committee of the Shanghai Tenth People's Hospital of Tongji University School of Medicine, and the requirement to obtain informed consent was waived. 


\section{Imaging procedures}

B-mode ultrasound, SE and point SWS measurement for thyroid were performed with the same S2000 ultrasound instrument (Siemens Medical Solutions, Mountain View, CA, USA). A 9L4-linear transducer (frequency range, 4-9 $\mathrm{MHz}$ ) was used for thyroid examination. The patients were placed in a supine position with dorsal flexion of the neck. The gain, focus position and depth of instrument were adjusted appropriately to ensure that the nodules displayed completely and conspicuously on the screen. Detailed procedures of examination were described previously [11].

\section{Image Interpretation}

All the images of B-mode ultrasound, SE, and point SWS measurement were analyzed in the same setting and in a blind manner by two experienced thyroid radiologists (B.J.L. and X.L.L.) .The identification of patients, clinical results and pathology results were anonymous to the investigators. In case of disagreement in the evaluation between the two radiologists, a third senior radiologist (B.D.C.) reviewed the images to make the final decision.

At B-mode ultrasound, the size of nodule was measured in longitudinal and transverse planes, and the largest dimension was used to measure the size of nodule. The other interpreted features of the nodule included: calcification (non-, micro-, or macro-calcification), echogenicity (hyper-, iso-, or hypo-echogenicity, and marked hypoechogenicity), shape (taller-than-wide or wider-than-tall), and margin (irregular, microlobulated, or well-defined). If a thyroid nodule had a combination of micro-calcification and macro-calcification, the nodule was classified as a macro-calcification nodule.

The conventional SE score of nodules was classified with a five-score system: score 1, the entire nodule is soft; score 2, part of nodule is hard; score 3, only margin of nodule is soft; score 4 , the entire nodule is hard; and score 5, the entire nodule and surrounding area are hard, according to the most recent guidelines and recommendations for clinical use of elastography by the World Federation for Ultrasound in Medicine and Biology [9]. Acoustic radiation force impulse (ARFI) SE grade for the thyroid nodules was divided into grade 1 to 6 : grade 1 , predominantly white; grade 2 , predominantly white with few black portions; grade 3 , black and white portion equally; grade 4 , predominantly black with a few white spots; grade 5, almost completely black, and grade 6 , completely dark, as we recently described [11].

For point SWS measurement, among 7 measured values of SWS for nodule and surrounding tissue, the maximum value of SWS was used as the first parameter. Then, the maximum and minimum values were eliminated, and the average of remaining 5 values was used as the second parameter of SWS. Previous reports have shown that five measurements were sufficient to assess thyroid stiffness [32, 33]. According to the manufacturer's suggestion and relevant reports $[11,34-36]$, the measurement result of "X.XX m/sec" was replaced by $0 \mathrm{~m} / \mathrm{s}$ or $8.4 \mathrm{~m} / \mathrm{s}$, with $0 \mathrm{~m} / \mathrm{s}$ corresponding to the cystic portion and $8.4 \mathrm{~m} / \mathrm{s}$ corresponding to the solid portion. The SWS ranged from $0.35 \mathrm{~m} / \mathrm{s}$ to $8.40 \mathrm{~m} / \mathrm{s}$ in this study.

\section{Statistical Analyses}

All the statistical analyses were performed with SPSS software (version 22.0; SPSS, Chicago, Ill) and MedCalc software (version 13.0; MedCalc,). Quantitative values were expressed as means \pm standard deviations (SD) and ranges. Nonparametric variables were analyzed by the Chi-square test, and continuous variables by independent $t$ test or one-way analysis of variance (ANOVA). The single and individual cutoff values of conventional SE score, ARFI SE grade and SWS were calculated by ROC curve yielding the maximum Youden index (YI) (i.e., sensitivity + specificity - 1), $90 \%$ sensitivity and $90 \%$ specificity $[25,27]$. The differences of cutoff values among different groups were tested by one-way ANOVA. The sensitivity, specificity, positive predictive value (PPV), negative predictive value (NPV) and YI were calculated applying the diagnostic $2 \times 2$ contingency tables. The diagnostic performances between single and individual cutoff values for thyroid nodules were compared by $\mathrm{Z}$ test. A two-tailed $P$ value $<0.05$ was considered statistically significant.

\section{CONFLICTS OF INTEREST}

The authors declare no conflicts of interest.

\section{GRANT SUPPORT}

This work was supported in part by the Shanghai Hospital Development Center (Grant SHDC12014229), the Science and Technology Commission of Shanghai Municipality (Grants 14441900900, 15411969000, and 16411971100), and the National Natural Scientific Foundation of China (Grants 81401417, 81601502, and 81501475).

\section{REFERENCES}

1. Davies L and Welch HG. Increasing incidence of thyroid cancer in the United States, 1973-2002. Jama. 2006; 295(18):2164-2167.

2. Davies L and Welch HG. Current thyroid cancer trends in the United States. JAMA Otolaryngol Head Neck Surg. 2014; 140(4):317-322.

3. Jiang H, Tian Y, Yan W, Kong Y, Wang H, Wang A, Dou J, Liang $\mathrm{P}$ and $\mathrm{Mu} \mathrm{Y}$. The Prevalence of Thyroid Nodules 
and an Analysis of Related Lifestyle Factors in Beijing Communities. International journal of environmental research and public health. 2016; 13(4):442.

4. Pellegriti G, Frasca F, Regalbuto C, Squatrito S and Vigneri R. Worldwide increasing incidence of thyroid cancer: update on epidemiology and risk factors. Journal of cancer epidemiology. 2013; 2013:965212.

5. American Thyroid Association Guidelines Taskforce on Thyroid N, Differentiated Thyroid C, Cooper DS, Doherty GM, Haugen BR, Kloos RT, Lee SL, Mandel SJ, Mazzaferri EL, McIver B, Pacini F, Schlumberger M, Sherman SI, Steward DL and Tuttle RM. Revised American Thyroid Association management guidelines for patients with thyroid nodules and differentiated thyroid cancer. Thyroid. 2009; 19(11):1167-1214.

6. Smith-Bindman R, Lebda P, Feldstein VA, Sellami D, Goldstein RB, Brasic N, Jin C and Kornak J. Risk of thyroid cancer based on thyroid ultrasound imaging characteristics: results of a population-based study. JAMA internal medicine. 2013; 173(19):1788-1796.

7. Schneider DF and Chen H. New developments in the diagnosis and treatment of thyroid cancer. CA Cancer J Clin. 2013; 63(6):374-394.

8. Barr RG, Nakashima K, Amy D, Cosgrove D, Farrokh A, Schafer F, Bamber JC, Castera L, Choi BI, Chou YH, Dietrich CF, Ding H, Ferraioli G, Filice C, Friedrich-Rust $\mathrm{M}$, Hall TJ, et al. WFUMB guidelines and recommendations for clinical use of ultrasound elastography: Part 2: breast. Ultrasound in medicine \& biology. 2015; 41(5):1148-1160.

9. Shiina T, Nightingale KR, Palmeri ML, Hall TJ, Bamber JC, Barr RG, Castera L, Choi BI, Chou Y-H, Cosgrove D, Dietrich CF, Ding H, Amy D, Farrokh A, Ferraioli G, Filice $\mathrm{C}$, et al. WFUMB Guidelines and Recommendations for Clinical Use of Ultrasound Elastography: Part 1: Basic Principles and Terminology. Ultrasound in medicine \& biology. 2015; 41(5):1126-1147.

10. Bamber J, Cosgrove D, Dietrich CF, Fromageau J, Bojunga J, Calliada F, Cantisani V, Correas JM, D'Onofrio M, Drakonaki EE, Fink M, Friedrich-Rust M, Gilja OH, Havre RF, Jenssen C, Klauser AS, et al. EFSUMB guidelines and recommendations on the clinical use of ultrasound elastography. Part 1: Basic principles and technology. Ultraschall in der Medizin (Stuttgart, Germany : 1980). 2013; 34(2):169-184.

11. Xu JM, Xu XH, Xu HX, Zhang YF, Zhang J, Guo LH, Liu LN, Liu C and Zheng SG. Conventional US, US elasticity imaging, and acoustic radiation force impulse imaging for prediction of malignancy in thyroid nodules. Radiology. 2014; 272(2):577-586.

12. Hamidi C, Goya C, Hattapoglu S, Uslukaya O, Teke M, Durmaz MS, Yavuz MS, Hamidi A and Tekbas G. Acoustic Radiation Force Impulse (ARFI) imaging for the distinction between benign and malignant thyroid nodules. La Radiologia medica. 2015; 120(6):579-583.

13. Samir AE, Dhyani M, Anvari A, Prescott J, Halpern EF,
Faquin WC and Stephen A. Shear-Wave Elastography for the Preoperative Risk Stratification of Follicular-patterned Lesions of the Thyroid: Diagnostic Accuracy and Optimal Measurement Plane. Radiology. 2015; 277(2):565-573.

14. Lin P, Chen M, Liu B, Wang S and Li X. Diagnostic performance of shear wave elastography in the identification of malignant thyroid nodules: a meta-analysis. European radiology. 2014; 24(11):2729-2738.

15. Kim MH, Luo S, Ko SH, Jung SL, Lim DJ and Kim Y. Elastography can effectively decrease the number of fine-needle aspiration biopsies in patients with calcified thyroid nodules. Ultrasound in medicine \& biology. 2014; 40(10):2329-2335.

16. Gregory A, Mehrmohammadi M, Denis M, Bayat M, Stan DL, Fatemi M and Alizad A. Effect of Calcifications on Breast Ultrasound Shear Wave Elastography: An Investigational Study. PloS one. 2015; 10(9):e0137898.

17. Veyrieres JB, Albarel F, Lombard JV, Berbis J, Sebag F, Oliver C and Petit P. A threshold value in Shear Wave elastography to rule out malignant thyroid nodules: a reality? European journal of radiology. 2012; 81(12):39653972.

18. Rago T, Santini F, Scutari M, Pinchera A and Vitti P. Elastography: new developments in ultrasound for predicting malignancy in thyroid nodules. The Journal of clinical endocrinology and metabolism. 2007; 92(8):29172922.

19. Lu Z, Mu Y, Zhu H, Luo Y, Kong Q, Dou J and Lu J. Clinical value of using ultrasound to assess calcification patterns in thyroid nodules. World journal of surgery. 2011; 35(1):122-127.

20. Kim BK, Choi YS, Kwon HJ, Lee JS, Heo JJ, Han YJ, Park YH and Kim JH. Relationship between patterns of calcification in thyroid nodules and histopathologic findings. Endocrine journal. 2013; 60(2):155-160.

21. Kwak JY, Han KH, Yoon JH, Moon HJ, Son EJ, Park SH, Jung HK, Choi JS, Kim BM and Kim EK. Thyroid imaging reporting and data system for US features of nodules: a step in establishing better stratification of cancer risk. Radiology. 2011; 260(3):892-899.

22. Papini E, Guglielmi R, Bianchini A, Crescenzi A, Taccogna S, Nardi F, Panunzi C, Rinaldi R, Toscano V and Pacella CM. Risk of malignancy in nonpalpable thyroid nodules: predictive value of ultrasound and color-Doppler features. The Journal of clinical endocrinology and metabolism. 2002; 87(5):1941-1946.

23. Haugen BR, Alexander EK, Bible KC, Doherty GM, Mandel SJ, Nikiforov YE, Pacini F, Randolph GW, Sawka AM, Schlumberger M, Schuff KG, Sherman SI, Sosa JA, Steward DL, Tuttle RM and Wartofsky L. 2015 American Thyroid Association Management Guidelines for Adult Patients with Thyroid Nodules and Differentiated Thyroid Cancer: The American Thyroid Association Guidelines Task Force on Thyroid Nodules and Differentiated Thyroid Cancer. Thyroid. 2016; 26(1):1-133. 
24. Frates $\mathrm{MC}$, Benson $\mathrm{CB}$, Doubilet PM, Kunreuther E, Contreras M, Cibas ES, Orcutt J, Moore FD, Jr., Larsen PR, Marqusee E and Alexander EK. Prevalence and distribution of carcinoma in patients with solitary and multiple thyroid nodules on sonography. The Journal of clinical endocrinology and metabolism. 2006; 91(9):34113417.

25. Greiner M, Pfeiffer D and Smith RD. Principles and practical application of the receiver-operating characteristic analysis for diagnostic tests. Preventive veterinary medicine. 2000; 45(1-2):23-41.

26. Tripepi G, Jager KJ, Dekker FW and Zoccali C. Diagnostic methods 2: receiver operating characteristic (ROC) curves. Kidney international. 2009; 76(3):252-256.

27. Schisterman EF, Perkins NJ, Liu A and Bondell H. Optimal Cut-point and Its Corresponding Youden Index to Discriminate Individuals Using Pooled Blood Samples. Epidemiology. 2005; 16(1):73-81.

28. Gu J, Du L, Bai M, Chen H, Jia X, Zhao J and Zhang $X$. Preliminary study on the diagnostic value of acoustic radiation force impulse technology for differentiating between benign and malignant thyroid nodules. Journal of ultrasound in medicine. 2012; 31(5):763-771.

29. Bhatia KS, Tong CS, Cho CC, Yuen EH, Lee YY and Ahuja AT. Shear wave elastography of thyroid nodules in routine clinical practice: preliminary observations and utility for detecting malignancy. European radiology. 2012; 22(11):2397-2406.

30. Hou XJ, Sun AX, Zhou XL, Ji Q, Wang HB, Wei H, Sun JW and Liu H. The application of Virtual Touch tissue quantification (VTQ) in diagnosis of thyroid lesions: a preliminary study. European journal of radiology. 2013; 82(5):797-801.
31. Liu BJ, Xu HX, Zhang YF, Xu JM, Li DD, Bo XW, Li $\mathrm{XL}$, Guo LH, Xu XH and Qu S. Acoustic radiation force impulse elastography for differentiation of benign and malignant thyroid nodules with concurrent Hashimoto's thyroiditis. Medical oncology. 2015; 32(3):50.

32. Fukuhara T, Matsuda E, Endo Y, Donishi R, Izawa S, Fujiwara K, Kitano H and Takeuchi H. Impact of Fibrotic Tissue on Shear Wave Velocity in Thyroid: An Ex Vivo Study with Fresh Thyroid Specimens. BioMed research international. 2015; 2015:569367.

33. Sporea I, Sirli R, Bota S, Vlad M, Popescu A and Zosin I. ARFI elastography for the evaluation of diffuse thyroid gland pathology: Preliminary results. World journal of radiology. 2012; 4(4):174-178.

34. Xu JM, Xu XH, Xu HX, Zhang YF, Guo LH, Liu LN, Liu C, Bo XW, Qu S, Xing M and Li XL. Prediction of cervical lymph node metastasis in patients with papillary thyroid cancer using combined conventional ultrasound, strain elastography, and acoustic radiation force impulse (ARFI) elastography. European radiology. 2016 ;26(8):2611-22.

35. Xu JM, Xu HX, Li XL, Bo XW, Xu XH, Zhang YF, Guo LH, Liu LN and Qu S. A Risk Model for Predicting Central Lymph Node Metastasis of Papillary Thyroid Microcarcinoma Including Conventional Ultrasound and Acoustic Radiation Force Impulse Elastography. Medicine. 2016; 95(3):e2558.

36. Zhang YF, Xu JM, Xu HX, Liu C, Bo XW, Li XL, Guo LH, Liu BJ, Liu LN and Xu XH. Acoustic Radiation Force Impulse Elastography: A Useful Tool for Differential Diagnosis of Thyroid Nodules and Recommending Fine-Needle Aspiration: A Diagnostic Accuracy Study. Medicine. 2015; 94(42):e1834. 